\title{
Real-world corticosteroid use in severe pneumonia: a propensity-score-matched study
}

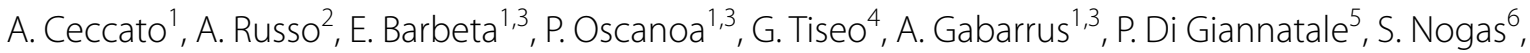 \\ C. Cilloniz ${ }^{1,3}$, F. Menichetti $^{4}$, M. Ferrer ${ }^{1,3}$, M. Niederman ${ }^{7}$, M. Falcone ${ }^{4}$ and A. Torres ${ }^{1,3^{*}}$ (D)
}

\begin{abstract}
Background: Community-acquired pneumonia (CAP) is a leading cause of morbidity and mortality worldwide despite correct antibiotic use. Corticosteroids have long been evaluated as a treatment option, but heterogeneous effects on survival have precluded their widespread implementation. We aimed to evaluate whether corticosteroids might improve clinical outcomes in patients with severe CAP and high inflammatory responses.

Study design and methods: We analyzed two prospective observational cohorts of patients with CAP in Barcelona and Rome who were admitted to intensive care with a high inflammatory response. Propensity score (PS) matching was used to obtain balance among the baseline variables in both groups, and we excluded patients with viral pneumonia or who received hydrocortisone.

Results: Of the 610 patients admitted with severe CAP, 198 (32\%) received corticosteroids and 387 had major criteria for severe CAP. All patients had a baseline serum C-reactive protein above $15 \mathrm{mg} / \mathrm{dL}$. Patients who received corticosteroids were more commonly male, had more comorbidities (e.g., cancer or chronic obstructive pulmonary disease), and presented with significantly higher sequential organ failure assessment scores. Eighty-nine patients met major severity criteria (invasive mechanical ventilation and/or septic shock) and were matched per group. Twenty-eightday mortality was lower among patients receiving corticosteroids (16 patients, 18\%) than among those not receiving them (28 patients, 31\%; $p=0.037$ ). After PS matching, corticosteroid therapy reduced the 28-day mortality risk in patients who met major severity criteria (hazard ratio (HR) 0.53 , 95\% confidence interval (Cl) 0.29-0.98) ( $p=0.043$ ). In patients who did not meet major severity criteria, no benefits were observed with corticosteroid use (HR $0.88(95 \% \mathrm{Cl}$ 0.32-2.36).
\end{abstract}

Conclusions: Corticosteroid treatment may be of benefit for patients with CAP who have septic shock and/or a high inflammatory response and requirement for invasive mechanical ventilation. Corticosteroids appear to have no impact on mortality when these features are not present.

Keywords: Community-acquired pneumonia, Corticosteroids, Mortality

\section{Background}

Community-acquired pneumonia (CAP) is a leading cause of mortality and morbidity worldwide despite correct antibiotic use [1, 2]. Severe disease not only

\footnotetext{
*Correspondence: atorres@ub.edu

${ }^{3}$ Department of Pneumology, Institut Clinic de Respiratori, Hospital Clinic of Barcelona, Villarroel 170, 08036 Barcelona, Spain

Full list of author information is available at the end of the article
}

manifests frequently and requires intensive care unit (ICU) admission [3, 4], but also presents with the highest mortality [5]. Death in severe CAP occurs due to an overwhelming pulmonary and systemic inflammatory response that causes abnormal gas exchange (i.e., respiratory failure), sepsis, and multiple-organ dysfunction [6]. Although antimicrobials are highly effective at reducing the bacterial burden of pulmonary infection [7], they do not directly modulate the inflammatory response.

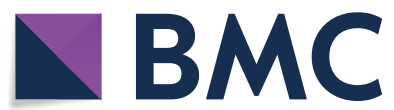

(c) The Author(s) 2021. Open Access This article is licensed under a Creative Commons Attribution 4.0 International License, which permits use, sharing, adaptation, distribution and reproduction in any medium or format, as long as you give appropriate credit to the original author(s) and the source, provide a link to the Creative Commons licence, and indicate if changes were made. The images or other third party material in this article are included in the article's Creative Commons licence, unless indicated otherwise in a credit line to the material. If material is not included in the article's Creative Commons licence and your intended use is not permitted by statutory regulation or exceeds the permitted use, you will need to obtain permission directly from the copyright holder. To view a copy of this licence, visit http://creativecommons.org/licenses/by/4.0/. The Creative Commons Public Domain Dedication waiver (http://creativeco mmons.org/publicdomain/zero/1.0/) applies to the data made available in this article, unless otherwise stated in a credit line to the data. 
Poor clinical outcomes in severe CAP necessitate treatment strategies other than antibiotics. Corticosteroids are a biologically plausible option that inhibit the expression and action of cytokines involved in the inflammatory response associated with pneumonia [8]. However, their use in CAP has yielded heterogeneous survival results in randomized clinical trials, in part because they included patients with and without severe CAP, precluding their routine inclusion in therapeutic strategies [9]. Appropriate selection of patients with severe CAP only, in whom the beneficial effects of corticosteroids outweigh the potential adverse effects, is therefore of major relevance $[10,11]$. Indeed, subgroup analyses of patients treated for CAP with corticosteroids have shown survival benefits mainly in those with severe disease. This is plausible because the low mortality in patients without severe CAP makes it less likely that we will observe reduced mortality [12-18]. Given that the rationale for corticosteroid use is to attenuate the inflammatory response, those with the highest inflammatory status should obtain the most benefit. In a randomized clinical trial of patients with severe CAP and high C-reactive protein (CRP) levels, corticosteroid use led to less late radiographic progression of pulmonary opacities [19]. However, this study was underpowered for assessing differences in mortality and other clinical outcomes.

We hypothesize that corticosteroids might improve clinical outcomes in patients with severe CAP and high inflammatory responses by reducing pulmonary and systemic inflammation. Accordingly, we aimed to analyze the impact of corticosteroids on mortality and other outcomes in patients with severe CAP and a high inflammatory response.

\section{Study design and methods}

This was an observational multicenter study in a realworld setting, using data from two prospective cohorts of consecutive patients with CAP admitted to the Hospital Clinic of Barcelona in Spain (January 2004 to December 2019) and the Policlinico Umberto I, "Sapienza" University of Rome in Italy (January 2015 to December 2017). The inclusion criteria were as follows: (a) adults aged $\geq 18$ years at diagnosis; (b) CAP confirmed by chest radiograph with consistent clinical manifestations (e.g., fever, cough, sputum production, and pleuritic chest pain); (c) patients admitted to ICU; (d) patients with a high inflammatory response, defined as a CRP $>15 \mathrm{mg} /$ $\mathrm{dL}$ at admission, based on the results of a previous study [19], (e) patients with major criteria for severe CAP according to ATS/IDSA criteria at baseline (24-48 h) [4]. The following exclusion criteria were also applied: (a) hospital admission for $\geq 48 \mathrm{~h}$ in the preceding 14 days; (b) absence of complete clinical follow-up data for
4-6 weeks; (c) severe immunosuppression, such as posttransplantation, HIV co-infection, or chemotherapy or immunosuppressive drug use ( $>20 \mathrm{mg}$ prednisone equivalent per day for $\geq 2$ weeks); (d) confirmed viral infection; and (e) hydrocortisone use.

\section{Ethics statement}

The ethics committees of the Hospital Clinic of Barcelona (Register: 5451) and of Policlinico Umberto I (register: 4065) approved the study and its publication. The need for written informed consent was waived because of the non-interventional design. Patient identities remained anonymous throughout.

\section{Data collection}

Details of comorbidities were obtained from medical records. Clinical, laboratory, and radiographic characteristics were recorded on admission (described in detail in Additional file 1: Content). During hospitalization, the following data were recorded: length of stay, need for mechanical ventilation (including whether invasive [IMC] or noninvasive [NIMV]), and 30-day mortality. Severe CAP was defined according to the American Thoracic Society and Infectious Diseases Society of America (ATS/IDSA) guidelines [20]. The Pneumonia Severity Index (PSI) [3] and Sepsis-related Organ Failure Assessment (SOFA) [21] scores were used to stratify cases by severity.

\section{Definitions}

Patients were grouped by their initial treatment into those who did and did not receive corticosteroids (prednisone, methylprednisolone, dexamethasone), which was considered to have been given if the patient received at least 72-h treatment with prednisone or an equivalent at a dosage of $\geq 30 \mathrm{mg} /$ day in the first $48 \mathrm{~h}$ of admission. Septic shock was defined according to the ATS/ IDSA pneumonia guidelines [4]. Empiric antimicrobial treatment was deemed appropriate when the isolated pathogens had in vitro susceptibility to at least one of the administered antimicrobials or follow ATS/IDSA guidelines [4] recommendation if no pathogen was isolated.

\section{Outcomes}

The main outcome was the 28-day all-cause mortality. The secondary outcome was the length of stay in hospital.

\section{Statistical analysis}

We reported the number and percentage of patients for categorical variables, the median and first and third quartiles for continuous variables with non-normal distributions, and the mean and standard deviation for continuous variables with normal distributions. Categorical 
variables were compared using Chi-square or Fisher exact tests, whereas continuous variables were compared using $t$-tests or nonparametric Mann-Whitney $U$ tests. All statistical analyses were performed using IBM SPSS Statistics, version 26.0 (IBM Corp., Armonk, NY, USA), and were considered significant at $p<0.05$ (two-tailed).

Propensity score (PS) matching [22, 23] was used to obtain balance between the corticosteroid (case) and non-corticosteroid (control) groups. In the total population, we used 1:1 nearest-neighbor matching without replacement within a match tolerance width of 0.001 ; in patients with IMV and/or shock and in patients without IMV nor shock, the match tolerance width was set at 0.005 . Variables were chosen for inclusion in the PS calculation according to the methods of Brookhart et al. [24], and we included those associated with the case group and outcome (Center, age, sex, diabetes mellitus, ischemic heart disease, hypertension, COPD, cancer, SOFA score, septic shock, and initial appropriate treatment). In the total population, adequate model fit with discrimination and calibration of the PS was demonstrated by logistic modeling including covariates (goodness-of-fit, $p=0.792$ ) and also in patients with IMV and/ or shock (goodness-of-fit, $p=0.614$ ) and in patients without IMV nor shock (goodness-of-fit, $p=0.715$ ). We performed three subgroup exploratory analyses for patients with septic shock only, IMV requirement only, and both septic shock and IMV requirement (see Additional file 1:
Content for further details). Multiple imputation [25] was used for missing covariates in PS matching.

Survival curves for patients with and without corticosteroids were obtained by the Kaplan-Meier method and compared using the Gehan-Breslow-Wilcoxon test. We used Cox proportional hazard regression models [26] for the 28-day mortality. Hazard ratios (HRs) and 95\% confidence intervals ( $95 \% \mathrm{CIs}$ ) were calculated.

\section{Results}

Of the 610 included patients, 198 (32\%) received corticosteroids (Fig. 1) and 387 had major criteria for severe CAP. Microbial isolation was reported in 227 patients (55\%) who did not receive corticosteroids and in 99 (50\%) who received corticosteroids. The most common microorganism was Streptococcus pneumoniae, followed by Staphylococcus aureus, Enterobacteriaceae, and Haemophilus influenzae. For the entire population, before PS matching, antibiotic treatment was appropriate for 302 patients (92\%) in the non-corticosteroid group and 115 patients $(86 \%)$ in the corticosteroid group (eTable 1).

The main baseline characteristics of patients with major criteria for severe CAP are described in Table 1. Patients who received corticosteroids were more commonly male, more often had comorbidities (e.g., diabetes mellitus, cancer or chronic obstructive pulmonary disease), presented significantly higher PSI and SOFA scores, and lower $\mathrm{PaO}_{2} / \mathrm{FiO}_{2}$, heart rate, and creatinine levels.

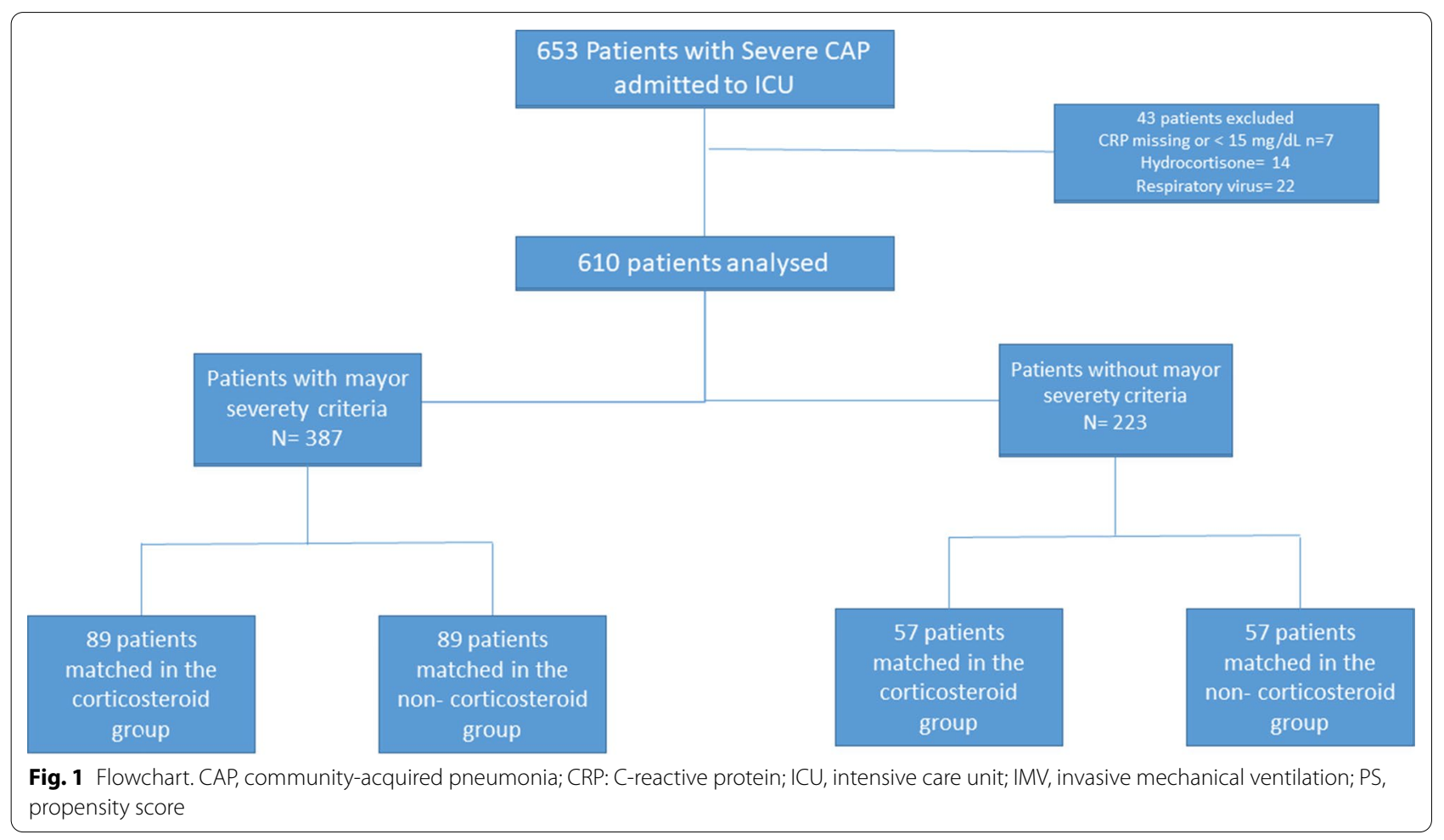


Table 1 Patient characteristics in the full cohort of patients with septic shock and/or IMV requirements and in the propensity score matching sample

\begin{tabular}{|c|c|c|c|c|c|c|}
\hline \multirow[t]{4}{*}{ Variable } & \multirow{2}{*}{\multicolumn{2}{|c|}{$\begin{array}{l}\text { Before PS matching ( } N=387 \\
\text { Corticosteroids }\end{array}$}} & \multirow[b]{4}{*}{$p$ value } & \multirow{2}{*}{\multicolumn{2}{|c|}{$\begin{array}{l}\text { After PS matching ( } N=178) \\
\text { Corticosteroids }\end{array}$}} & \multirow[b]{4}{*}{$p$ value } \\
\hline & & & & & & \\
\hline & \multirow{2}{*}{$\begin{array}{l}\text { No } \\
N=268\end{array}$} & \multirow{2}{*}{$\begin{array}{l}\text { Yes } \\
N=119\end{array}$} & & \multirow{2}{*}{$\begin{array}{l}\text { No } \\
N=89\end{array}$} & \multirow{2}{*}{$\begin{array}{l}\text { Yes } \\
N=89\end{array}$} & \\
\hline & & & & & & \\
\hline Age (years), median (Q1; Q3) & $68.5(54.5 ; 80)$ & $72(59 ; 81)$ & 0.126 & $73(56 ; 84)$ & $72(59 ; 83)$ & 0.839 \\
\hline Male sex, $n(\%)$ & $115(43)$ & $68(57)$ & 0.010 & $50(56)$ & $48(54)$ & 0.763 \\
\hline Current smoking habit, $n(\%)$ & $86(33)$ & $34(30)$ & 0.489 & $27(32)$ & $24(28)$ & 0.616 \\
\hline Current alcohol abuse, $n(\%)$ & $37(21)$ & $8(13)$ & 0.190 & $10(21)$ & $6(13)$ & 0.273 \\
\hline \multicolumn{7}{|l|}{ Comorbidities, $n$ (\%) } \\
\hline Diabetes mellitus & $63(24)$ & $17(14)$ & 0.033 & $15(17)$ & $15(17)$ & 1.000 \\
\hline Ischemic heart disease & $31(18)$ & $21(18)$ & 0.880 & $13(15)$ & $13(15)$ & 1.000 \\
\hline Hypertension & $64(38)$ & $56(47)$ & 0.110 & $36(40)$ & $37(42)$ & 0.879 \\
\hline COPD & $58(22)$ & $41(35)$ & 0.012 & $27(30)$ & $27(30)$ & 1.000 \\
\hline Cancer & $32(12)$ & $25(21)$ & 0.028 & $11(12)$ & $13(15)$ & 0.661 \\
\hline SOFA score, median (Q1; Q3) & $5(3 ; 6)$ & $5(4 ; 7)$ & 0.003 & $5(4 ; 7)$ & $5(3 ; 7)$ & 0.483 \\
\hline Pneumonia Severity Index, median (Q1; Q3) & $127.5(107 ; 154.5)$ & $140(119 ; 163)$ & 0.007 & $140(121 ; 157)$ & $135(116 ; 159)$ & 0.500 \\
\hline $\mathrm{PaO}_{2} / \mathrm{FiO}_{2}<250, n(\%)$ & $110(42)$ & $70(59)$ & 0.003 & $51(44)$ & $51(57)$ & 0.415 \\
\hline Altered mental status, $n(\%)$ & $83(31)$ & $31(26)$ & 0.296 & $39(44)$ & $23(26)$ & 0.010 \\
\hline Respiratory rate, median (Q1; Q3) & $28(24 ; 32)$ & $26(21 ; 30)$ & 0.058 & $28(20 ; 35)$ & $25(20 ; 30)$ & 0.276 \\
\hline Heart rate, median (Q1; Q3) & $110(28 ; 95)$ & $100(81 ; 114)$ & 0.004 & $107(90 ; 130)$ & $98(85 ; 111)$ & 0.034 \\
\hline Temperature $\left({ }^{\circ} \mathrm{C}\right)$, median $(\mathrm{Q} 1 ; \mathrm{Q} 3)$ & $37(36.2 ; 38)$ & $37.4(36.7 ; 38)$ & 0.161 & $37(36.3 ; 38)$ & $37.4(36.8 ; 38)$ & 0.092 \\
\hline Creatinine (mg/dL), median (Q1; Q3) & $1.4(1 ; 1.9)$ & $1.2(0.8 ; 1.6)$ & 0.001 & $1.3(1 ; 1.9)$ & $1.1(0.8 ; 1.6)$ & 0.032 \\
\hline $\mathrm{CRP}(\mathrm{mg} / \mathrm{dl})$, median $(\mathrm{Q} 1 ; \mathrm{Q} 3)$ & $29(23.1 ; 37.1)$ & $30.3(24.4 ; 44.1)$ & 0.274 & $29.4(24.8 ; 37.3)$ & $30(24.3 ; 43.9)$ & 0.961 \\
\hline White blood cell count (109 cells/L), median (Q1; Q3) & $12.6(7.6 ; 19)$ & $14.6(7.9 ; 20.9)$ & 0.259 & $12.8(6.4 ; 17.9)$ & $16(9.2 ; 20.7)$ & 0.131 \\
\hline Need of IMV, $n(\%)$ & $134(52)$ & $50(42)$ & 0.073 & $42(50)$ & $32(36)$ & 0.062 \\
\hline Septic shock, $n(\%)$ & $197(74)$ & $107(90)$ & 0.001 & $74(83)$ & $79(89)$ & 0.281 \\
\hline Polymicrobial infection, $n$ (\%) & $8(3)$ & $10(8)$ & 0.020 & $4(4)$ & $8(9)$ & 0.232 \\
\hline Initial appropriate treatment, $n$ (\%) & $237(92)$ & $97(88)$ & 0.319 & $78(88)$ & $85(96)$ & 0.059 \\
\hline
\end{tabular}

Boldface entries indicate statistical significance

CAP, community-acquired pneumonia; COPD, chronic obstructive pulmonary disease; CRP: C-reactive protein; DM, Diabetes mellitus; IHD, ischemic heart disease; IMV, invasive mechanical ventilation; PS, propensity score; Q1, first quartile; Q3, third quartile; SOFA: Sequential Organ Failure Assessment. Percentages calculated with non-missing data only. $p$ values marked in bold indicate numbers that are statistically significant on the $95 \%$ confidence limit

Antibiotic treatment was appropriate for 302 patients (92\%) in the non-corticosteroid group and 115 patients $(86 \%)$ in the corticosteroid group (Table 1). No significant differences were found in all outcome variables.

PS matching was performed in patients with major criteria for severe CAP, resulting in 89 patients per group with significant differences in mental status and creatinine level alterations. The 28-day mortality was lower among patients who received corticosteroids (16 patients [18\%]) than among those who did not (28 patients [31\%]; $p<0.05)$. Cox regression analyses revealed that corticosteroids reduced the 28-day mortality risk, giving an HR of 0.53 (95\% CI 0.29-0.98). The Kaplan-Meier survival curves for patients receiving IMV and/or experiencing shock are shown in Fig. 2.

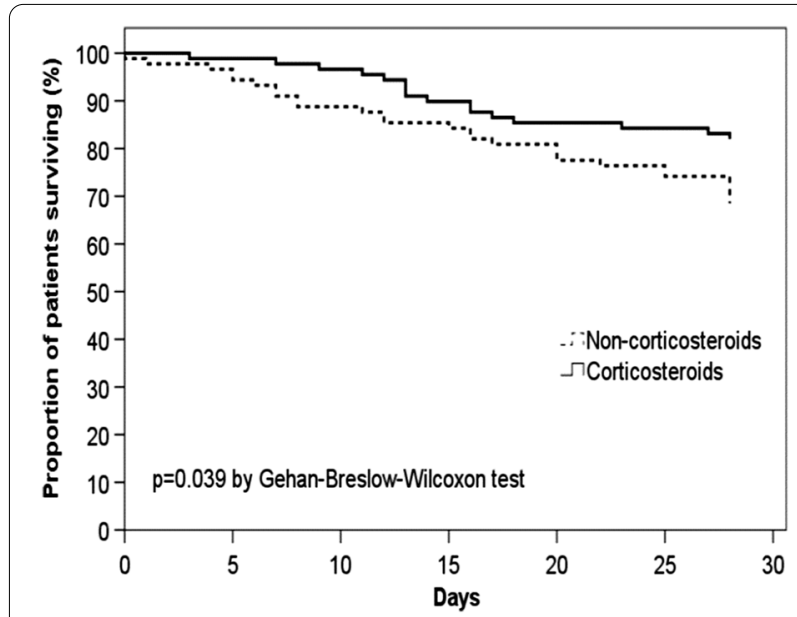

Fig. 2 Kaplan-Meier survival curve after PS matching 
For patients who did not meet major criteria for severe CAP, PS matching resulted in 57 patients per group. Twenty-eight-day mortality was similar between groups $(16 \%[n=9]$ in the corticosteroid group vs $18 \%[n=10]$ in the non-corticosteroid group, HR $0.88 \quad(95 \%$ CI 0.32-2.36).

Sensitivity analysis was performed in all patients admitted to the ICU and did not find significant differences between groups (etable 2).

Among patients who received corticosteroids, hospital stay was shorter only in those who met major severity criteria (Table 2).

\section{Discussion}

In the present study, mortality benefits were only observed among the most severely ill patients with CAP receiving corticosteroid therapy. The 28-day mortality did not differ with corticosteroids use in either the matched or unmatched analysis for patients in ICU with a high inflammatory response; however, when we analyzed only patients who required IMV and/or presented septic shock, mortality was significantly lower among those who received corticosteroids. These data from a multinational and real-world setting support the results of a prior meta-analysis.

Corticosteroid treatment for CAP is a controversial topic. Despite several studies showing improved outcomes, such as less treatment failure, shorter hospital stays, shorter time to clinical stability $[19,27]$, or reduced risk of cardiovascular events [28], only one has shown improved mortality [29]. This may be because many studies have lacked the statistical power to find significance differences. Improved mortality has been observed in several meta-analyses, mainly for severe CAP $[15,16,30-$ 32 ], but concerns about non-reproducible results and differences in baseline characteristics have been raised for the two studies $[29,33]$ with the greatest positive results that drove the conclusions. A major limitation of these studies and meta-analyses is the fact that different criteria were used for severe pneumonia (i.e., admission to ICU, ATS/IDSA criteria, septic shock, invasive mechanical ventilation requirement, or high severity scores). These differences have led to contradictory suggestions in clinical practice guidelines. While guidelines for the diagnosis and management of critical illness-related corticosteroid insufficiency (CIRCI) by the Society of Critical Care Medicine and European Society of Intensive Care Medicine favor corticosteroid use in CAP [34], ATS/ IDSA guidance for CAP management continues to advise against corticosteroid use [4].

We took care to select only those patients who could benefit from corticosteroids. Corticosteroids are thought to immunomodulate the disproportionate inflammatory response, so we only included patients with a measurably elevated inflammatory response $(\mathrm{CRP}>15 \mathrm{mg} / \mathrm{dL})$ $[19,35]$. We excluded patients with viral pneumonia because several analyses have shown that corticosteroids may increase mortality in patients admitted for severe influenza [36]; however, this is somewhat controversial because dexamethasone has been shown to reduce mortality in patients with COVID-19 [37, 38]. Patients who received hydrocortisone were excluded as well, based on the results of a meta-analysis showing that patients who received hydrocortisone did not present benefits in terms of mortality [39].

We found reduced mortality associated with corticosteroid use in only the patients considered most severely ill according to the ATS/IDSA criteria. Corticosteroids have been evaluated in other related severe diseases, such as acute respiratory distress syndrome (ARDS) [40] or septic shock, with those results also open to debate. In the last Surviving Sepsis campaign, it was stated that corticosteroids were indicated in cases of septic shock when hemodynamic stability was not achieved despite adequate fluid resuscitation and vasopressor support [41]. Recent positive results

Table 2 Outcomes in the full cohort of patients with septic shock and/or IMV requirements and in the propensity score matching sample

\begin{tabular}{|c|c|c|c|c|c|c|}
\hline & \multicolumn{3}{|c|}{ Before PS matching $(N=387)$} & \multicolumn{3}{|c|}{ After PS matching $(N=178)$} \\
\hline & \multicolumn{2}{|c|}{ Corticosteroids } & \multirow[b]{3}{*}{$p$ value } & \multicolumn{2}{|c|}{ Corticosteroids } & \multirow[b]{3}{*}{$p$ value } \\
\hline & No & Yes & & No & Yes & \\
\hline & $N=268$ & $N=119$ & & $N=89$ & $N=89$ & \\
\hline 28-day mortality, $n$ (\%) & $65(24)$ & $24(20)$ & 0.368 & $28(31)$ & $16(18)$ & 0.037 \\
\hline $\begin{array}{l}\text { Hospital length of stay (days), } \\
\text { median (Q1; Q3) }\end{array}$ & $17(10 ; 28)$ & $14(10 ; 25)$ & 0.216 & $17(10.5 ; 29)$ & $13(9 ; 20)$ & 0.027 \\
\hline
\end{tabular}


when using dexamethasone in ARDS have re-opened the debate about corticosteroid use in this setting [40]. We did not find any difference in 28-day mortality in specific sub-populations (septic shock or IMV requirements alone) when analyzed separately, but we could only match small numbers of patients in each group, which makes it difficult to reach a firm conclusion. Further studies are needed to evaluate if corticosteroids reduce the risk of death in CAP by reducing pulmonary inflammation or improving hemodynamic parameters.

A major strength of the present research is that we could reproduce, in a real-world, multinational setting, results that have previously only been shown in metaanalyses. However, our study still had several limitations. First, the observational design means that patients may have received corticosteroids for a reason other than severe CAP. Although we tried to recreate the conditions of a clinical trial as far as possible, corticosteroid treatments were not protocoled, and so patients who received corticosteroids were not homogeneous in terms of time until first corticosteroid dose, total dose, and type of corticosteroids. Second, despite exhaustive PS matching for underlying conditions, severity criteria, treatment adequacy, center, etc., some differences remained between the groups. Finally, we established time windows to include or exclude patients. These time windows can be found in previous clinical trials; however, in our case they may have led us to select certain patients and not others. Nevertheless, these limitations also reflect the reallife scenario. Our results must be considered with care, given the controversial results in clinical trials (including one unpublished trial, NCT01283009). However, they may help to develop new clinical trials including only the most severely ill populations with high inflammatory responses.

\section{Conclusions}

The mortality benefits of corticosteroid treatment for CAP, as previously reported in a meta-analysis, only appear to be observed in the most severely ill patients who have a high inflammatory response in real-world settings. In the absence of patients with severe CAP having an IMV requirement or developing septic shock, corticosteroids are not associated with lower mortality.

\footnotetext{
Abbreviations

ATS/IDSA: American Thoracic Society and Infectious Diseases Society of America; CAP: Community-acquired pneumonia; CIRCI: Critical illness-related corticosteroid insufficiency; CRP: C-reactive protein; ICU: Intensive care unit; IMV: Invasive mechanical ventilation; PSI: Pneumonia Severity Index; PS: Propensity score; SOFA: Sepsis-related Organ Failure Assessment.
}

\section{Supplementary Information}

The online version contains supplementary material available at https://doi. org/10.1186/s13054-021-03840-x.

Additional file 1. Supplementary Online Content with additional methods, baseline charachteristics and outcomes is available.

\section{Acknowledgements}

We are indebted to all our medical and nursing colleagues for their assistance and cooperation in this study. We thank Elisabeth Sancho for her administrative support. We thank Michael Maudsley (University of Barcelona) for his assistance in reviewing the language of the manuscript.

\section{Authors' contributions}

$A C, E B, A G$, and $A T$ were involved in the conception and design; AC, AR, EB, CC, $\mathrm{PO}, \mathrm{PD}, \mathrm{SN}$, and MFerrer contributed to the acquisition, analysis, or interpretation of data; AC, GT, FM, MN, MFalcone, and AT contributed to the drafting of the manuscript for important intellectual content; AG was involved in the statistical analysis; AC provided the administrative, technical or material support; AT contributed to the study supervision. All authors reviewed, revised, and approved the manuscript for submission.

\section{Funding}

This study was supported by CIBERES and IDIBAPS. The funding sources had no role in the design and conduct of the study; the collection, management, analysis, and interpretation of the data; the preparation, review, or approval of the manuscript; or the decision to submit the manuscript for publication.

\section{Availability data and materials}

The datasets used and/or analyzed during the current study are available from the corresponding author on reasonable request.

\section{Declarations}

Ethics approval and consent to participate

The ethics committees of the Hospital Clinic of Barcelona (Register: 5451) and of Policlinico Umberto I (register: 4065) approved the study and its publication. The need for written informed consent was waived because of the noninterventional design. Patient identities remained anonymous throughout.

\section{Consent for publication}

Not applicable.

\section{Competing interests}

The authors have disclosed that they do not have any conflicts of interest.

\section{Author details}

${ }^{1}$ Ciber de Enfermedades Respiratorias (Ciberes, CB06/06/0028), Institut d'Investigacions Biomèdiques August Pi I Sunyer (IDIBAPS), University of Barcelona (UB), Barcelona, Spain. ${ }^{2}$ Department of Public Health and Infectious

Diseases, Policlinico Umberto I, "Sapienza" University of Rome, Rome, Italy.

${ }^{3}$ Department of Pneumology, Institut Clinic de Respiratori, Hospital Clinic of Barcelona, Villarroel 170, 08036 Barcelona, Spain. ${ }^{4}$ Infectious Diseases Unit, Department of Clinical and Experimental Medicine, University of Pisa, Pisa, Italy. ${ }^{5}$ Department of Medical, Oral and Biotechnological Sciences, School of Medicine and Health Sciences, Section of Anesthesia Analgesia, Perioperative and Intensive Care, SS. Annunziata Hospital, Gabriele d'Annunzio University of Chieti-Pescara, Chieti, Italy. ${ }^{6}$ Dipartimento Scienze Chirurgiche E Diagnostiche Integrate (DISC), Università Degli Studi Di Genova, Genova, Italy. ${ }^{7}$ Division of Pulmonary and Critical Care Medicine, Weill Cornell Medical College, New York Presbyterian/Weill Cornell Medical Center, New York, NY, USA.

Received: 8 September 2021 Accepted: 24 November 2021

Published online: 16 December 2021 


\section{References}

1. Prina E, Ranzani OT, Torres A. Community-acquired pneumonia. Lancet Lond Engl. 2015;386(9998):1097-108.

2. Dambrava PG, Torres A, Vallès X, Mensa J, Marcos MA, Peñarroja G, et al. Adherence to guidelines' empirical antibiotic recommendations and community-acquired pneumonia outcome. Eur Respir J. 2008;32(4):892-901.

3. Fine MJ, Auble TE, Yealy DM, Hanusa BH, Weissfeld LA, Singer DE, et al. A prediction rule to identify low-risk patients with community-acquired pneumonia. N Engl J Med. 1997:336(4):243-50.

4. Metlay JP, Waterer GW, Long AC, Anzueto A, Brozek J, Crothers K, et al. Diagnosis and treatment of adults with community-acquired pneumonia. An official clinical practice guideline of the American thoracic society and infectious diseases society of America. Am J Respir Crit Care Med. 2019;200(7):e45-67.

5. Ferrer M, Travierso C, Cilloniz C, Gabarrus A, Ranzani OT, Polverino E, et al. Severe community-acquired pneumonia: Characteristics and prognostic factors in ventilated and non-ventilated patients. PLOS ONE. 2018;13(1):e0191721.

6. Menéndez R, Cavalcanti M, Reyes S, Mensa J, Martinez R, Marcos MA, et al. Markers of treatment failure in hospitalised community acquired pneumonia. Thorax. 2008;63(5):447-52.

7. Jones RN, Farrell DJ, Mendes RE, Sader HS. Comparative ceftaroline activity tested against pathogens associated with community-acquired pneumonia: results from an international surveillance study. J Antimicrob Chemother. 2011;66(Suppl 3):iii69-80.

8. Rhen T, Cidlowski JA. Antiinflammatory action of glucocorticoids-new mechanisms for old drugs. N Engl J Med. 2005:353(16):1711-23.

9. Torres A, Ferrer M, Niederman MS. Adjuvant therapies in critical care: steroids in community-acquired pneumonia. Intensive Care Med. 2018:44(4):478-81.

10. Prina E, Ceccato A, Torres A. New aspects in the management of pneumonia. Crit Care Lond Engl. 2016:20(1):267.

11. Ceccato A, Ferrer M, Barbeta E, Torres A. Adjunctive therapies for community-acquired pneumonia. Clin Chest Med. 2018;39(4):753-64

12. Marti C, Grosgurin O, Harbarth S, Combescure C, Abbas M, Rutschmann $O$, et al. Adjunctive corticotherapy for community acquired pneumonia: a systematic review and meta-analysis. PLoS ONE [Internet]. 2015 Dec 7 [cited 2021 Mar 1];10(12). https://www.ncbi.n/m.nih.gov/pmc/articles/PMC46 71611/

13. Siempos II, Vardakas KZ, Kopterides P, Falagas ME. Adjunctive therapies for community-acquired pneumonia: a systematic review. J Antimicrob Chemother. 2008;62(4):661-8.

14. Nie W, Zhang Y, Cheng J, Xiu Q. Corticosteroids in the treatment of community-acquired pneumonia in adults: a meta-analysis. PLoS ONE. 2012;7(10):e47926.

15. Siemieniuk RAC, Meade MO, Alonso-Coello P, Briel M, Evaniew N, Prasad $\mathrm{M}$, et al. Corticosteroid therapy for patients hospitalized with communityacquired pneumonia: a systematic review and meta-analysis. Ann Intern Med. 2015;163(7):519-28.

16. Horita N, Otsuka T, Haranaga S, Namkoong H, Miki M, Miyashita N, et al. Adjunctive systemic corticosteroids for hospitalized community-acquired pneumonia: systematic review and meta-analysis 2015 update. Sci Rep [Internet]. 2015;5. https://www.ncbi.nlm.nih.gov/pmc/articles/PMC45 $71641 /$

17. Wan Y-D, Sun T-W, Liu Z-Q, Zhang S-G, Wang L-X, Kan Q-C. Efficacy and safety of corticosteroids for community-acquired pneumonia: a systematic review and meta-analysis. Chest. 2016;149(1):209-19.

18. Briel M, Spoorenberg SMC, Snijders D, Torres A, Fernandez-Serrano S, Meduri $\mathrm{GU}$, et al. Corticosteroids in patients hospitalized with community-acquired pneumonia: systematic review and individual patient data metaanalysis. Clin Infect Dis Off Publ Infect Dis Soc Am. 2018;66(3):346-54.

19. Torres A, Sibila O, Ferrer M, Polverino E, Menendez R, Mensa J, et al. Effect of corticosteroids on treatment failure among hospitalized patients with severe community-acquired pneumonia and high inflammatory response: a randomized clinical trial. JAMA. 2015;313(7):677-86.

20. Mandell LA, Wunderink RG, Anzueto A, Bartlett JG, Campbell GD, Dean NC, et al. Infectious Diseases Society of America/American Thoracic Society consensus guidelines on the management of community-acquired pneumonia in adults. Clin Infect Dis Off Publ Infect Dis Soc Am. 2007;1 (44 Suppl 2):S27-72.

21. Vincent JL, Moreno R, Takala J, Willatts S, De Mendonça A, Bruining H, et al. The SOFA (Sepsis-related Organ Failure Assessment) score to describe organ dysfunction/failure. On behalf of the Working Group on Sepsis-Related Problems of the European Society of Intensive Care Medicine. Intensive Care Med. 1996:22(7):707-10

22. Austin PC. An introduction to propensity score methods for reducing the effects of confounding in observational studies. Multivar Behav Res. 2011;46(3):399-424.

23. Rosenbaum PR, Rubin DB. The central role of the propensity score in observational studies for causal effects. Biometrika. 1983;70(1):41-55.

24. Brookhart MA, Schneeweiss S, Rothman KJ, Glynn RJ, Avorn J, Stürmer T. Variable selection for propensity score models. Am J Epidemiol. 2006;163(12):1149-56.

25. Sterne JAC, White IR, Carlin JB, Spratt M, Royston P, Kenward MG, et al. Multiple imputation for missing data in epidemiological and clinical research: potential and pitfalls. BMJ. 2009;338:b2393.

26. Collet D. Modelling survival data in medical research. 2nd edn. London; 1994

27. Blum CA, Nigro N, Briel M, Schuetz P, Ullmer E, Suter-Widmer I, et al. Adjunct prednisone therapy for patients with community-acquired pneumonia: a multicentre, double-blind, randomised, placebo-controlled trial. Lancet Lond Engl. 2015;385(9977):1511-8.

28. Cangemi R, Falcone M, Taliani G, Calvieri C, Tiseo G, Romiti GF, et al. Corticosteroid use and incident myocardial infarction in adults hospitalized for community-acquired pneumonia. Ann Am Thorac Soc. 2019;16(1):91-8.

29. Confalonieri M, Urbino R, Potena A, Piattella M, Parigi P, Puccio G, et al. Hydrocortisone infusion for severe community-acquired pneumonia: a preliminary randomized study. Am J Respir Crit Care Med. 2005;171(3):242-8.

30. Stern A, Skalsky K, Avni T, Carrara E, Leibovici L, Paul M. Corticosteroids for pneumonia. Cochrane Database Syst Rev. 2017;12:CD007720.

31. Wu W-F, Fang Q, He G-J. Efficacy of corticosteroid treatment for severe community-acquired pneumonia: a meta-analysis. Am J Emerg Med. 2017;

32. Bi J, Yang J, Wang Y, Yao C, Mei J, Liu Y, et al. Efficacy and safety of adjunctive corticosteroids therapy for severe community-acquired pneumonia in adults: an updated systematic review and meta-analysis. PLOS ONE. 2016;11(11):e0165942.

33. Nafae RM, Ragab MI, Amany FM, Rashed SB. Adjuvant role of corticosteroids in the treatment of community-acquired pneumonia. Egypt J Chest Dis Tuberc. 2013;62(3):439-45.

34. Pastores SM, Annane D, Rochwerg B, Esicm and the CGTF of S and. Guidelines for the Diagnosis and Management of Critical Illness-Related Corticosteroid Insufficiency (CIRCI) in Critically III Patients (Part II): Society of Critical Care Medicine (SCCM) and European Society of Intensive Care Medicine (ESICM) 2017. Crit Care Med. 2018:46(1):146.

35. Urwyler SA, Blum CA, Coslovsky M, Mueller B, Schuetz P, Christ-Crain M. Cytokines and Cortisol_-predictors of treatment response to corticosteroids in community-acquired pneumonia? J Intern Med. 2019;286(1):75-87.

36. Moreno G, Rodríguez A, Reyes LF, Gomez J, Sole-Violan J, Díaz E, et al. Corticosteroid treatment in critically ill patients with severe influenza pneumonia: a propensity score matching study. Intensive Care Med. 2018:44(9):1470-82.

37. Dexamethasone in hospitalized patients with Covid-19. N Engl J Med 2021;384(8):693-704.

38. Association between administration of systemic corticosteroids and mortality among critically ill patients with COVID-19: a meta-analysis|Critical Care Medicine|JAMA|JAMA Network [Internet]. [cited 2021 Mar 10]. https://jaman etwork.com/journals/jama/fullarticle/2770279

39. Huang J, Guo J, Li H, Huang W, Zhang T. Efficacy and safety of adjunctive corticosteroids therapy for patients with severe community-acquired pneumonia: a systematic review and meta-analysis. Medicine (Baltimore). 2019;98(13):e14636.

40. Villar J, Ferrando C, Martínez D, Ambrós A, MuñozT, Soler JA, et al. Dexamethasone treatment for the acute respiratory distress syndrome: a multicentre, randomised controlled trial. Lancet Respir Med. 2020:8(3):267-76.

41. Rhodes A, Evans LE, Alhazzani W, Levy MM, Antonelli M, Ferrer R, et al. Surviving sepsis campaign: international guidelines for management of sepsis and septic shock: 2016. Intensive Care Med. 2017;43(3):304-77.

\section{Publisher's Note}

Springer Nature remains neutral with regard to jurisdictional claims in published maps and institutional affiliations. 